\title{
Development and Validation of RP-HPLC Method for Simultaneous Estimation of Aspirin and Esomeprazole Magnesium in Tablet Dosage Form
}

\author{
Dipali Patel, Nishitkumar Patel, Reeta Vaishy, Viral Patel, Chiragsinh Solanki, and Mitul Patel \\ Department of Quality Assurance, Indubhai Patel College of Pharmacy and Research Centre, Dharmaj, Gujarat 388430, India \\ Correspondence should be addressed to Dipali Patel, saldip_2327@yahoo.com
}

Received 29 June 2012; Revised 5 November 2012; Accepted 12 November 2012

Academic Editor: Nianjun Yang

Copyright (C) 2013 Dipali Patel et al. This is an open access article distributed under the Creative Commons Attribution License, which permits unrestricted use, distribution, and reproduction in any medium, provided the original work is properly cited.

\begin{abstract}
A simple, specific, precise, and accurate reversed-phase HPLC method was developed and validated for simultaneous estimation of aspirin and esomeprazole magnesium in tablet dosage forms. The separation was achieved by HyperChrom ODS-BP $\mathrm{C}_{18}$ column $(200 \mathrm{~mm} \times 4.6 \mathrm{~mm} ; 5.0 \mu \mathrm{m})$ using acetonitrile: methanol: $0.05 \mathrm{M}$ phosphate buffer at $\mathrm{pH} 3$ adjusted with orthophosphoric acid $(25: 25: 50, \mathrm{v} / \mathrm{v})$ as eluent, at a flow rate of $1 \mathrm{~mL} / \mathrm{min}$. Detection was carried out at wavelength $230 \mathrm{~nm}$. The retention times of aspirin and esomeprazole magnesium were $4.29 \mathrm{~min}$ and $6.09 \mathrm{~min}$, respectively. The linearity was established over the concentration ranges of $10-70 \mu \mathrm{g} / \mathrm{mL}$ and $10-30 \mu \mathrm{g} / \mathrm{mL}$ with correlation coefficients $\left(r^{2}\right) 0.9986$ and 0.9973 for aspirin and esomeprazole magnesium, respectively. The mean recoveries were found to be in the ranges of $99.80-100.57 \%$ and $99.70-100.83 \%$ for aspirin and esomeprazole magnesium, respectively. The proposed method has been validated as per ICH guidelines and successfully applied to the estimation of aspirin and esomeprazole magnesium in their combined tablet dosage form.
\end{abstract}

\section{Introduction}

Aspirin (ASP) is chemically 2-(acetyloxy)-benzoic acid (Figure 1). It is nonselective cyclooxygenase inhibitor used as an antipyretic, analgesic, anti-inflammatory, and antithrombotic agent. Esomeprazole magnesium (ESO) is $\mathrm{S}$-isomer of omeprazole and proton pump inhibitor. It is magnesium, bis [5-methoxy-2-[[(4-methoxy-3,5-dimethyl-2pyridinyl)methyl]sulfinyl]-1H-benzimidazolato] (Figure 2). It is used in treatment of peptic ulcer disease, NSAIDSassociated ulceration and Zollinger-Ellison syndrome, used as antiulcerative. ASP and ESO in combined dosage form are used in cardiovascular disorder and cerebrovascular disorders [1-3].

The review of literature revealed that various analytical methods involving spectrophotometry [4-6], HPLC [7-10] and HPTLC [11] have been reported for ASP in single form and in combination with other drugs. Several analytical methods have been reported for ESO in single form and in combination with other drugs including spectrophotometry $[12,13]$, HPLC $[14,15]$, and HPTLC [16].
The present work describes the development of a simple, precise, accurate, and reproducible HPLC method for the simultaneous estimation of ASP and ESO in combined dosage form. The developed method was validated in accordance with ICH Guidelines [17] and successfully employed for the assay of ASP and ESO combine dosage form.

\section{Experimental Condition}

2.1. Materials and Reagents. Analytically pure ASP and ESO were kindly provided by Baroque Pharmaceuticals, Khambhat, Gujarat, India and Osaka Pharmaceuticals, Sakarda, Vadodara, Gujarat, India, respectively, as gift samples. Analytical grade methanol, chloroform, acetonitrile, glacial acetic acid, and ethyl acetate were purchased from SD Fines Chemicals, Bombay, India. Tablet of ASP and ESO in combined dosage form, AXANUM, with a $20 \mathrm{mg}$ ESO and $81 \mathrm{mg}$ ASP label claim, manufactured by Astrazeneca Pharmaceuticals.

2.2. Instrumentation. An isocratic HPLC system (Analytical Technologies Limited) consisted of P2230 plus HPLC 
<smiles>CC(=O)Oc1ccccc1C(=O)O</smiles>

FIGURE 1: Structure of aspirin.

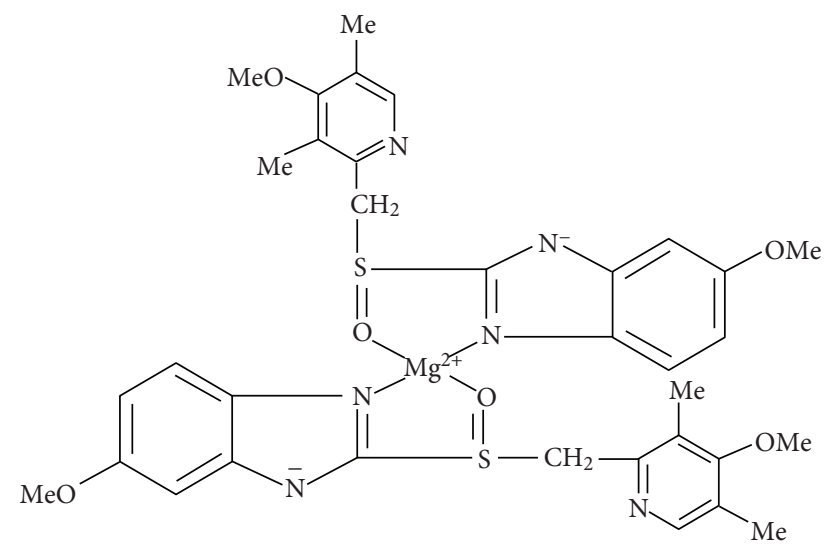

FIGURE 2: Structure of esomeprazole magnesium.

pump, variable wavelength programmable UV 2230 plus detector system, Rhenodyne valve with $20 \mu \mathrm{L}$ fixed loop and Analchrom 2006 as operating software. The chromatographic column used was HyperChrom ODS-BP $\mathrm{C}_{18}$ column $(200 \mathrm{~mm} \times 4.6 \mathrm{~mm}$ i.d, particle size $5 \mu \mathrm{m})$. Analytical balance K-EA 210 (K-Roy Instrument Pvt. Ltd) was used for weighing purpose.

2.3. Chromatographic Condition. A mixture of Acetonitrile: Methanol:0.05 M Phosphate Buffer at $\mathrm{pH} 3$ adjusted with orthophosphoric acid $(25: 25: 50 \mathrm{v} / \mathrm{v})$ was used as mobile phase and was filtered through $0.45 \mu$ membrane filter prior to use. The flow rate of mobile phase was maintained at $1 \mathrm{~mL} / \mathrm{min}$. Detection was carried out at $230 \mathrm{~nm}$ at the ambient temperature. The total run time $10 \mathrm{~min}$ was used with injection volume of $20 \mu \mathrm{L}$.

2.4. Preparation of Mobile Phase and Standard Stock Solutions. Accurately weighed potassium dihydrogen phosphate $(3.4 \mathrm{~g})$ was dissolved in $500 \mathrm{~mL}$ of water. This solution was mixed with $250 \mathrm{~mL}$ of acetonitrile and $250 \mathrm{~mL}$ of methanol. Finally the $\mathrm{pH}$ was adjusted to 3.0 with orthophosphoric acid. The solution was sonicated for 10 minutes and filtered through $0.45 \mu$ membrane filter. $100 \mathrm{mg}$ of standard ASP and ESO were accurately weighed and transferred separately to a $100 \mathrm{~mL}$ volumetric flask and dissolved in $50 \mathrm{~mL}$ mobile phase. The flask was sonicated for $10 \mathrm{~min}$. The flask was shaken and volume was made up to the mark with mobile phase to give a solution containing $1000 \mu \mathrm{g} / \mathrm{mL}$ ASP and ESO, respectively. Appropriate volume of aliquot from ASP

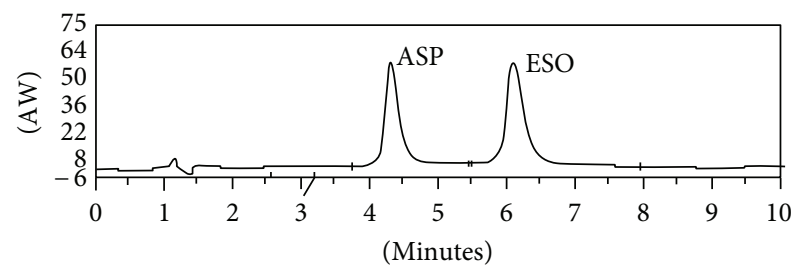

FIgURE 3: Chromatogram of mixed standard solution containing $10 \mu \mathrm{g} / \mathrm{mL}$ ESO and $10 \mu \mathrm{g} / \mathrm{mL}$ ASP using mobile phase acetonitrile: methanol:0.05 $\mathrm{M}$ phosphate buffer at $\mathrm{pH} 3$ adjusted with orthophosphoric acid $(25: 25: 50 \mathrm{v} / \mathrm{v})$.

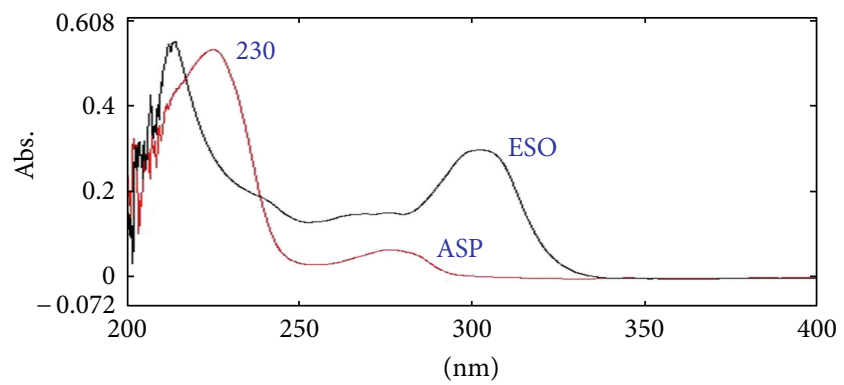

FIgURE 4: Overlain spectrum of $10 \mu \mathrm{g} / \mathrm{mL}$ ASP and $5 \mu \mathrm{g} / \mathrm{mL}$ ESO in methanol.

TABLE 1: Summary of validation parameters.

\begin{tabular}{lcc}
\hline Parameters & ASP & ESO \\
\hline Recovery \% & $99.80-100.57$ & $99.70-100.83$ \\
Repeatability (C.V., $n=6)$ & 0.205123 & 0.537209 \\
$\begin{array}{l}\text { Precision (\% RSD) } \\
\quad \text { Intra-day }(n=3)\end{array}$ & $0.14-0.38$ & $0.22-0.49$ \\
$\quad$ Inter-day $(n=3)$ & $0.38-0.83$ & $0.22-0.86$ \\
$\begin{array}{l}\text { Limit of detection }(\mu \mathrm{g} / \mathrm{mL}) \\
\text { Limit of quantitation } \\
(\mu \mathrm{g} / \mathrm{mL})\end{array}$ & 3.25067 & 2.09632 \\
Specificity & 9.85051 & 6.35250 \\
Robustness & Specific & Specific \\
Solvent stability & Robust & Robust \\
\hline
\end{tabular}

TABLE 2: Calibration data for ASP and ESO.

\begin{tabular}{lcc}
\hline Parameter & ASP & ESO \\
\hline Linear range $(\mu \mathrm{g} / \mathrm{mL})$ & $10-70$ & $10-30$ \\
Slope & 89.00785 & 93.47274 \\
Intercept & -237.786 & 23.3054 \\
Standard deviation of slope & 1.93647 & 2.79913 \\
Standard deviation of intercept & 87.67731 & 59.37857 \\
\hline
\end{tabular}

and ESO standard stock solution was further diluted with mobile phase to obtain final concentration of $100 \mu \mathrm{g} / \mathrm{mL}$ and $100 \mu \mathrm{g} / \mathrm{mL}$, respectively. 
TABLE 3: Robustness study.

\begin{tabular}{|c|c|c|c|c|c|}
\hline \multirow{2}{*}{ Condition varied } & \multirow{2}{*}{ Changed condition } & \multicolumn{2}{|c|}{ Area $(n=3)$} & \multicolumn{2}{|c|}{$\%$ Assay } \\
\hline & & $\mathrm{ESO} \pm$ S.D. & ASP \pm S.D. & ESO & ASP \\
\hline \multirow{2}{*}{ Change in mobile phase ratio $(\mathrm{v} / \mathrm{v})$} & $28: 22: 50$ & $1299.76 \pm 4.90$ & $4797.53 \pm 12.33$ & 98.01 & 99.91 \\
\hline & $22: 28: 50$ & $1310.43 \pm 5.60$ & $4782.56 \pm 15.12$ & 100.82 & 99.68 \\
\hline
\end{tabular}

TABLE 4: System suitability test parameter.

\begin{tabular}{lcc}
\hline $\begin{array}{l}\text { System suitability } \\
\text { parameters }\end{array}$ & \multicolumn{2}{c}{ ESoposed Method } \\
\hline $\begin{array}{l}\text { Retention times }\left(R_{T}\right) \\
(\text { min }) \pm \text { S.D. }\end{array}$ & $6.088 \pm 0.10740$ & $4.286 \pm 0.03983$ \\
$\begin{array}{l}\text { Theoretical plates } \\
(N) \pm \text { S.D. }\end{array}$ & $3063.4 \pm 25.8438$ & $2535.4 \pm 5.8242$ \\
Resolution $\left(R_{S}\right)$ & & 4.62 \\
Tailing factor & $1.364 \pm 0.07197$ & $1.412 \pm 0.05167$ \\
$\left(A_{S}\right) \pm$ S.D. & 5.088 & 3.286 \\
Capacity factor & & \\
\hline
\end{tabular}

\subsection{Determination of ESO and ASP from Combined Dosage Form}

2.5.1. Sample Preparation. A powder quantity equivalent to $40 \mathrm{mg}$ ESO and $162 \mathrm{mg}$ ASP was accurately weighed and transferred to volumetric flask of $100 \mathrm{~mL}$ capacity. $60 \mathrm{~mL}$ of solvent (acetonitrile: methanol: water $(25: 25: 50)$ ) was transferred to this volumetric flask and sonicated for $15 \mathrm{~min}$. The flask was shaken and volume was made up to the mark with methanol. The above solution was filtered through membrane filter $(0.45 \mu)$. From this solution $3.5 \mathrm{~mL}$ was transferred to volumetric flask of $100 \mathrm{~mL}$ capacity. Volume was made up to the mark to give a solution containing $14 \mu \mathrm{g} / \mathrm{mL}$ of ESO and $56.7 \mu \mathrm{g} / \mathrm{mL}$ of ASP. The resulting solution was analyzed by proposed method. The prepared sample solution was chromatographed for 10 minutes using mobile phase at a flow rate of $1.0 \mathrm{~mL} / \mathrm{min}$. From the peak area obtained in the chromatogram, the amounts of both the drugs were calculated.

\section{Method Validation}

The proposed method has been extensively validated in terms of specificity, linearity, accuracy, precision, limits of detection (LOD) and quantification (LOQ), robustness, and system suitability. The accuracy was expressed in terms of percent recovery of the known amount of the standard drugs added to the known amount of the pharmaceutical dosage forms. The precision (\% RSD) was expressed with respect to the repeatability, intraday, and interday variation in the expected drug concentrations. After validation, the developed methods have been applied to pharmaceutical dosage form.

3.1. Specificity. Commonly used excipients (starch, microcrystalline cellulose, and magnesium stearate) were spiked into a preweighed quantity of drugs. The chromatogram was taken by appropriate dilutions and the quantities of drugs were determined.

3.2. Linearity. Appropriate volume of aliquot from ASP and ESO standard stock solution was transferred to same volumetric flask of $10 \mathrm{~mL}$ capacity. The volume was adjusted to the mark with mobile phase to give a solution containing ASP $(10,25,40,55$, and $70 \mu \mathrm{g} / \mathrm{mL})$ and ESO $(10,15$, 20,25 , and $30 \mu \mathrm{g} / \mathrm{mL}$ ). The mixed standard solution was chromatographed using above chromatoghraphic condition $(n=6)$. All solutions were filtered through $0.45 \mu \mathrm{m}$ filter prior to use. Calibration curves were constructed by plotting average peak area versus concentrations for both drugs. Straight line equations were obtained from these calibration curves.

3.3. Accuracy. Accuracy was assessed by determination of the recovery of the method by addition of standard drug to preanalyzed test sample preparation at 3 different concentration levels 80,100 , and $120 \%$, taking into consideration percentage purity of added bulk drug samples. Each concentration was chromatographed 3 times and average recoveries were measured.

3.4. Precision. The repeatability was evaluated by assaying 6 times of test samples prepared for assay determination. The intraday and interday precision study of ASP and ESO was carried out by estimating different concentrations of ASP and $\mathrm{ESO}, 3$ times on the same day and on 3 different days and the results are reported in terms of \% RSD.

3.5. Detection Limit and Quantitation Limit. ICH guideline describes several approaches to determine the detection and quantitation limits. These include visual evaluation, signalto-noise ratio, and the use of standard deviation of the response and the slope of the calibration curve. In the present study, the LOD and LOQ were based on the third approach and were calculated according to the $3.3 \mathrm{\sigma} / \mathrm{s}$ and $10 \mathrm{\sigma} / \mathrm{s}$ criterions, respectively, where $\sigma$ is the standard deviation of $y$-intercepts of regression lines and $s$ is the slope of the calibration curve.

3.6. Robustness. The robustness of the method was evaluated by assaying test solutions after slight but deliberate changes in the analytical conditions. For the proposed method it was done by changing the mobile phase composition (acetonitrile : methanol : buffer, $28: 22: 50$ and $22: 28: 50$, v/v by observing the stability of the drugs for $24 \mathrm{hr}$ in the mobile phase. 
TABLE 5: Assay results of marketed formulation.

\begin{tabular}{lccccr}
\hline \multirow{2}{*}{ Formulation } & \multicolumn{2}{c}{ Actual concentration $\mu \mathrm{g} / \mathrm{mL}$} & \multicolumn{2}{c}{ Amount obtained $\mu \mathrm{g} / \mathrm{mL}$} & \multirow{2}{*}{$\%$ ESO } \\
& ESO & ASP & ESO & ASP & \% ASP \\
\hline Tablet & 14 & 56.7 & 13.92 & 56.55 & 99.42 \\
\hline
\end{tabular}

3.7. System Suitability. The suitability of the chromatographic system was tested before each stage of validation. Five replicate injections of standard preparation were injected and resolution, asymmetry, number of theoretical plates, and relative standard deviation of peak area were determined.

3.8. Determination of ASP and ESO from Combined Dosage Form. Sample solution was injected 6 times at above chromatographic conditions. An average peak area was measured from chromatograms. The quantitation was carried out by keeping these values to the straight line equation of calibration curve.

\section{Results and Discussion}

Optimizations of chromatographic conditions were performed to obtain the best resolution and peak parameter (asymmetry, theoretical plates). For the selection of mobile phase initially methanol-water and acetonitrile-water have been tried in different ratio which gave poor peak shape. Then acetonitrile : methanol: $0.050 \mathrm{M}$ potassium dihydrogen phosphate buffer adjusted to $\mathrm{pH} 3.0$ in different ratio have been tried. Finally, acetonitrile : methanol : $0.05 \mathrm{M}$ phosphate buffer at $\mathrm{pH} 3$ adjusted with orthophosphoric Acid $(25: 25: 50 \mathrm{v} / \mathrm{v})$ was found to be satisfactory and gave two symmetrical peaks with good resolution (4.62) for ASP and ESO at flow rate of $1 \mathrm{~mL} / \mathrm{min}$. The average retention times for ASP and ESO were $4.286 \pm 0.03983$ and $6.088 \pm 0.10740 \mathrm{~min}-$ utes, respectively. The asymmetric factors for ASP and ESO were $1.412 \pm 0.05167$ and $1.364 \pm 0.07197$, respectively. For the selection of detection wavelength overlain UV spectrum of ASP and ESO was taken which revealed that at $230 \mathrm{~nm}$ both the drugs possess significant absorbance (Tables 3 and 4; Figures 3 and 4).

Summary of validation parameters for proposed method was given in Table 1.

The developed HPLC method was validated. The linear range, correlation coefficient, detection limit and standard deviation for ASP and ESO by HPLC method are shown in Table 2. Accuracy was determined by calculating the recovery. The method was found to be accurate with \% recovery $99.80-100.57 \%$ for ASP and $99.70-100.83 \%$ for ESO respectively.

Precision was calculated as repeatability and intra and interday variation for both the drugs. The method was precise with \% RSD $0.14-0.38$ for intraday $(n=3)$ and \% RSD $0.38-0.83$ for interday $(n=3)$ for ASP and $0.22-0.49$ for intraday $(n=3)$ and \% RSD $0.22-0.86$ for interday $(n=3)$ for ESO, respectively.

The method was specific as no interference observed when the drugs were estimated in presence of excipients.
The method was also robust as there was no change in area up to 24 hours of preparation of solution in acetonitrile: methanol:0.05 $\mathrm{M}$ phosphate buffer at $\mathrm{pH} 3$ adjusted with orthophosphoric acid $(25: 25: 50 \mathrm{v} / \mathrm{v})$. The LOD for ASP and ESO was found to be $3.25 \mu \mathrm{g} / \mathrm{mL}$ and $2.09 \mu \mathrm{L} / \mathrm{mL}$, respectively. Summary of validation parameters is tabulated in Table 1. Marketed formulation was analyzed by the proposed method and assay result of marketed formulation was shown in Table 5.

\section{Conclusion}

The proposed HPLC method provide simple, specific, precise, accurate, and reproducible quantitative analysis for simultaneous analysis of ASP and ESO in combined dosage form. The method was validated as per ICH guidelines in terms of specificity, linearity, accuracy, precision, limits of detection (LOD) and quantification (LOQ), robustness, and reproducibility. The proposed method can be used for routine analysis and quality control assay of ESO and ASP in combined dosage form.

\section{Acknowledgments}

The authors are thankful to Osaka Pharmaceuticals (Vadodara, India) for providing gratis sample with great pleasure and a note of thanks to Baroque Pharmaceuticals (Khambhat, India) for providing gratis sample with great pleasure. The authors are also thankful to Indubhai Patel College of Pharmacy and Research Centre (Dharmaj, India) for providing the necessary facilities for research work.

\section{References}

[1] Martindale-the Complete Drug Reference, Pharmaceutical Press, London, UK, 34th edition, 2005.

[2] M. J. O'Neil, Ed., The Merk Index- An Encyclopedia of Chemicals, Drugs and Biological, Merck Research Laboratories, 14th edition, 2006.

[3] Antithrombotic Trialists' (ATT) Collaboration, "Aspirin in the primary and secondary prevention of vascular disease: collaborative meta-analysis of individual participant data from randomised trials," The Lancet, vol. 373, no. 9678, pp. 1849-1860, 2009.

[4] M. D. Game, K. B. Gabhane, and D. M. Sakarkar, "Quantitative analysis of clopidogrel bisulphate and aspirin by first derivative spectrophotometric method in tablets," Indian Journal of Pharmaceutical Sciences, vol. 72, no. 6, pp. 825-828, 2010.

[5] Z. Kokot and K. Burda, "Simultaneous determination of salicylic acid and acetylsalicylic acid in aspirin delayed-release tablet formulations by second-derivative UV spectrophotometry," Journal of Pharmaceutical and Biomedical Analysis, vol. 18, no. 4-5, pp. 871-875, 1998. 
[6] P. Mishra and A. Dolly, "Simultaneous determination of clopidogrel and aspirin in pharmaceutical dosage forms," Indian Journal of Pharmaceutical Sciences, vol. 68, no. 3, pp. 365-368, 2006.

[7] D. Shah, K. Bhatt, R. Mehta, M. Shankar, S. Baldania, and T. Gandhi, "Development and validation of a RP-HPLC method for determination of atorvastatin calcium and aspirin in a capsule dosage form," Indian Journal of Pharmaceutical Sciences, vol. 69, no. 4, pp. 546-549, 2007.

[8] E. R. Montgomery, S. Taylor, J. Segretario, E. Engler, and D. Sebastian, "Development and validation of a reversedphase liquid chromatographic method for analysis of aspirin and warfarin in a combination tablet formulation," Journal of Pharmaceutical and Biomedical Analysis, vol. 15, no. 1, pp. 73-82, 1996.

[9] E. Deconinck, P. Y. Sacré, S. Baudewyns, P. Courselle, and J. De Beer, "A fast ultra high pressure liquid chromatographic method for qualification and quantification of pharmaceutical combination preparations containing paracetamol, acetyl salicylic acid and/or antihistaminics," Journal of Pharmaceutical and Biomedical Analysis, vol. 56, no. 2, pp. 200-209, 2011.

[10] S. L. Yang, L. O. Wilken, and C. R. Clark, "A high performance liquid chromatographic method for the simultaneous assay of aspirin, caffeine, dihydrocodeine bitartrate and promethazine hydrochloride in a capsule formulation," Drug Development and Industrial Pharmacy, vol. 11, no. 4, pp. 799-814, 1985.

[11] P. K. Sinha, M. C. Damle, and K. G. Bothara, "A validated stability indicating HPTLC method for determination of aspirin and clopidogrel bisulphate in combined dosage form," Eurasian Journal of Analytical Chemistry, vol. 4, no. 2, pp. 152-160, 2009.

[12] S. S. Patil, P. N. Dhabale, and B. Kuchekar, "Development and statistical validation of spectrophotometric method for estimation of esomeprazole in tablet dosage form," Asian Journal of Research in Chemistry, vol. 2, no. 2, pp. 154-156, 2009.

[13] V. V. Gawande and A. V. Chandewar, "Spectroscopic estimation of esomeprazole magnesium in solid dosage form," International Journal of Pharmacy \& Technology, vol. 2, no. 3, pp. 617-622, 2010.

[14] A. Önal and A. Öztunç, "Development and validation of high performance liquid chromatographic method for the determination of esomeprazole in tablets," Journal of Food and Drug Analysis, vol. 14, no. 1, pp. 12-18, 2006.

[15] P. Sripal Reddy, S. Sait, G. Vasudevmurthy, B. Vishwanath, V. Prasad, and S. Jayapal Reddy, "Stability indicating simultaneous estimation of assay method for naproxen and esomeprazole in pharmaceutical formulations by RP-HPLC," Der Pharma Chemica, vol. 3, no. 6, pp. 553-564, 2011.

[16] S. Sharma and M. C. Sharma, "Densitometric method for the Quantitative determination of Esomeprazole and Domperidon," American-Eurasian Journal of Toxicological Science, vol. 3, no. 3, pp. 143-148, 2011.

[17] ICH Harmonized Tripartite Guidelines, Validation of Analytical Procedures: Text and Methodology, Q2 (R1), Geneva, Switzerland, 2005. 

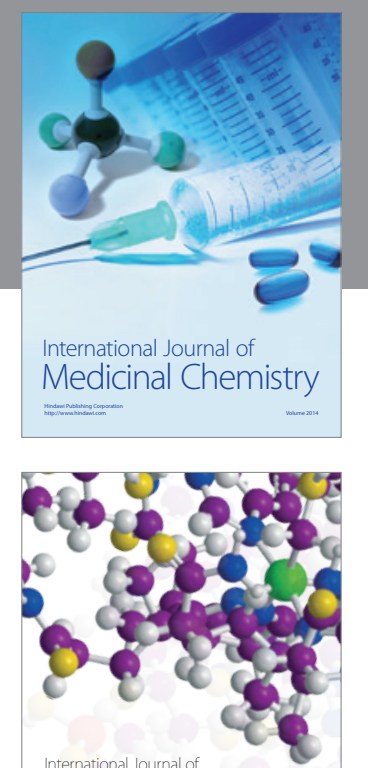

\section{Carbohydrate} Chemistry

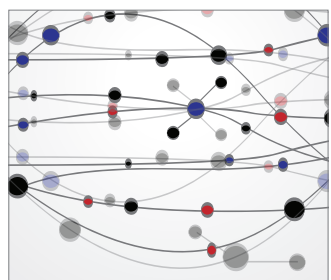

The Scientific World Journal
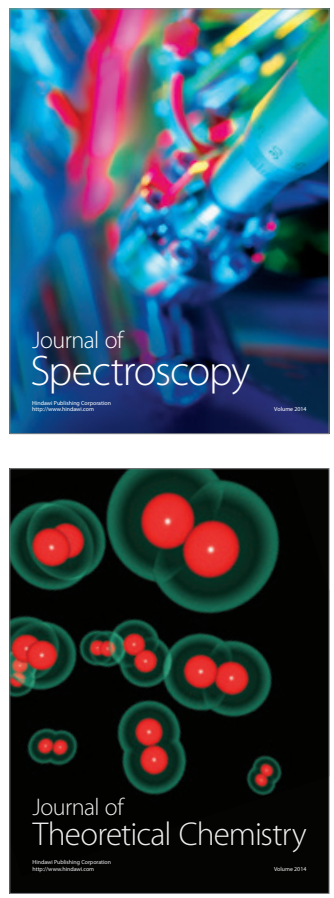
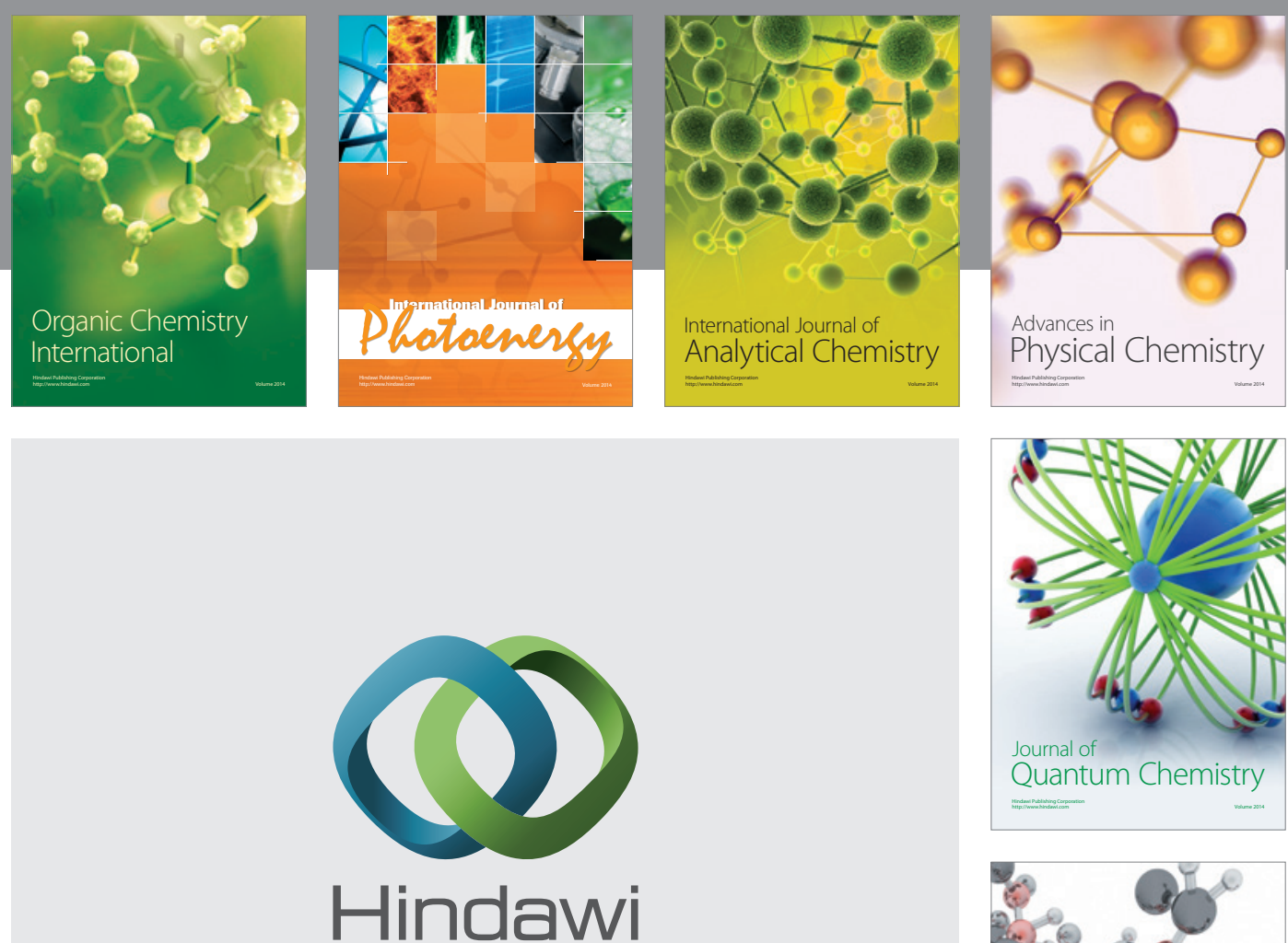

Submit your manuscripts at

http://www.hindawi.com

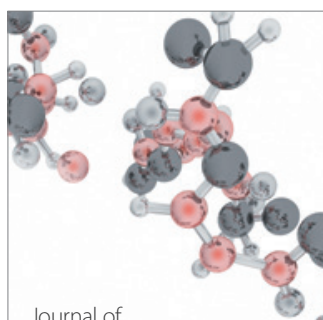

Analytical Methods

in Chemistry

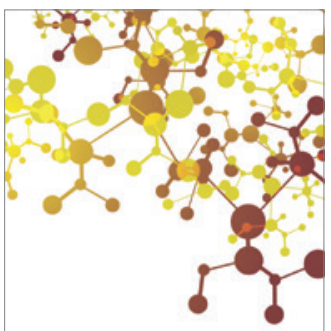

Journal of

Applied Chemistry

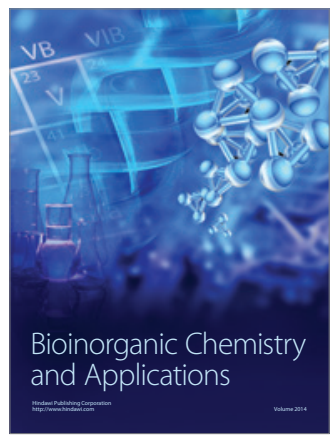

Inorganic Chemistry
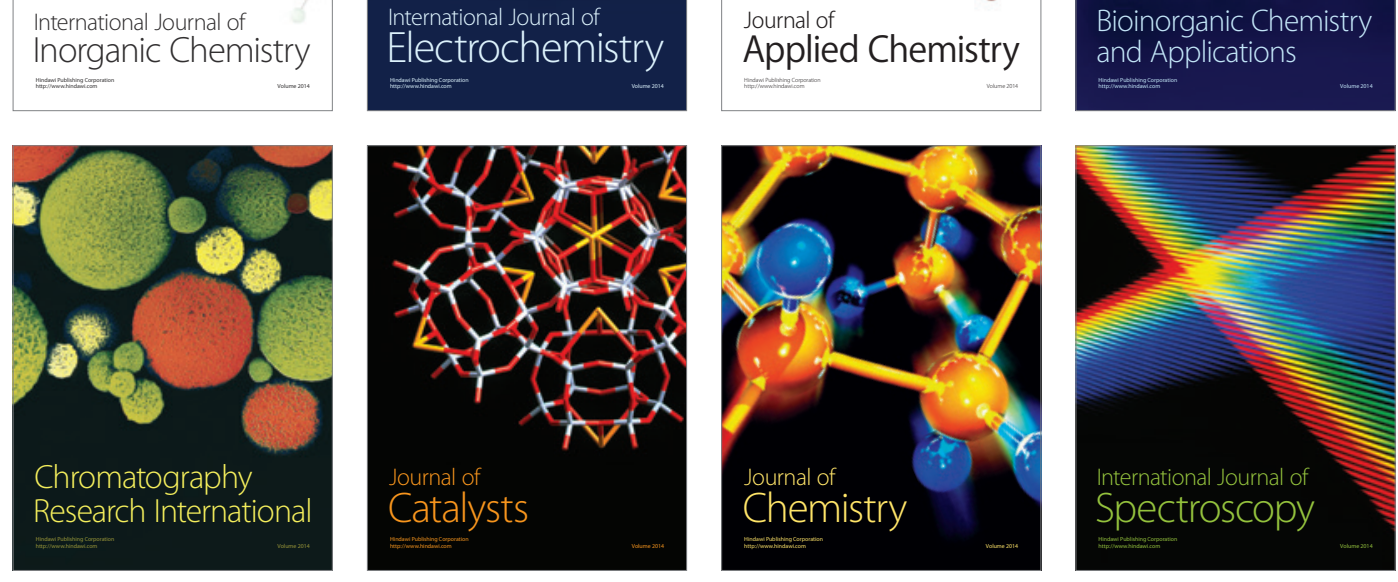